\title{
The pre- and postoperative illness trajectory in patients with pituitary tumours
}

\author{
Eva Jakobsson Ung 1,2,3, Ann-Charlotte Olofsson ${ }^{3}$, Ida Björkman ${ }^{1,2}$, Tobias Hallén ${ }^{4,5}$, Daniel S Olsson ${ }^{3,6}$, \\ Oskar Ragnarsson ${ }^{3,6}$, Thomas Skoglund ${ }^{4,5}$, Sofie Jakobsson ${ }^{1,2, *}$ and Gudmundur Johannsson ${ }^{3,6, *}$ \\ ${ }^{1}$ Institute of Health and Care Sciences, Sahlgrenska Academy at the University of Gothenburg, Gothenburg, Sweden \\ ${ }^{2}$ Centre for Person-Centred Care (GPCC), University of Gothenburg, Gothenburg, Sweden \\ ${ }^{3}$ Department of Medicine, Sahlgrenska University Hospital, Gothenburg, Sweden \\ ${ }^{4}$ Department of Neurosurgery, Sahlgrenska University Hospital, Gothenburg, Sweden \\ ${ }^{5}$ Institute of Neuroscience and Physiology, University of Gothenburg, Sahlgrenska Academy, Gothenburg, Sweden \\ ${ }^{6}$ Department of Internal Medicine and Clinical Nutrition, Institute of Medicine, Sahlgrenska Academy, University of Gothenburg, Gothenburg, Sweden
}

Correspondence should be addressed to G Johannsson: gudmundur.johannsson@medic.gu.se

*(S Jakobsson and G Johannsson contributed equally to this work)

\begin{abstract}
Objective: Experiences and need of support during surgery and start of replacement therapy in patients with pituitary tumours are highly unknown. This study aimed at exploring patient experiences during pre- and postoperative care and recovery after pituitary surgery in patients with a pituitary tumour.

Methods: Within a qualitative study design, 16 consecutive patients who underwent surgery for pituitary tumours were repeatedly interviewed. In total, 42 interviews were performed before and after surgery. Analysis was performed using qualitative interpretation.

Results: Suffering a pituitary tumour was overwhelming for many patients and struggling with existential issues was common. Patients expressed loneliness and vulnerability before and after surgery. How professionals handled information in connection with diagnosis greatly affected the patients. Other patients with the same diagnosis were experienced as the greatest support. Normalisation of bodily symptoms and relationships with others were reported during postoperative recovery. However, a fear that the tumour would return was present.

Conclusions: Patients with pituitary tumours need structured support, including peer support, which acknowledges physical, cognitive as well as emotional and existential concerns. Information related to diagnosis and surgery should be adapted in relation to the loneliness and the existential seriousness of the situation. Care and support for patients with pituitary tumours should preferably be organised based on continuity and an unbroken care pathway from the first pre-operative evaluation through to postoperative care and the start of a life-long endocrine treatment and tumour surveillance.
\end{abstract}

\section{Introduction}

Pituitary tumours are rare; for example, the annual incidence of non-functioning pituitary adenomas is 0.65-2.34 per $100,000(1,2,3)$. Although most pituitary tumours are benign, patients often need to undergo surgery and also, sometimes, radiotherapy $(4,5)$. The tumours and/or its treatment are associated with excess mortality and morbidity $(3,6,7,8,9)$. The consequences of both the tumour and surgery and/or radiotherapy may https://ec.bioscientifica.com https://doi.org/10.1530/EC-19-0202 (c) 2019 The authors Published by Bioscientifica Ltd

\author{
Key Words \\ - pituitary tumour \\ - non-functioning pituitary \\ illness \\ - qualitative research \\ - surgery
}


lead to hypopituitarism and a need for life-long hormone replacement therapy (4). Hypopituitarism may lead to various physical and mental symptoms depending on the degree of hormone deficiency $(2,4,10)$. Studies in adults with hypopituitarism have shown that cognitive problems, including reduced ability to concentrate and memory disturbances, are common in patients with pituitary tumours $(11,12)$, which subsequently impair quality of life (13). Approximately, $30-50 \%$ of patients with non-functioning pituitary adenoma who undergo surgery have tumour remnants needing longterm surveillance and, possibly, additional therapeutic intervention (14). Patients with pituitary tumours therefore have a complex, life-long disease which they need to master and manage in their daily life due to their tumour burden and its endocrine and neurological consequences. This complexity leads to a life-long contact with healthcare professionals.

Research on patients with pituitary tumours has mainly focused on the consequences of hypopituitarism and cardiovascular health as well as the efficacy and safety of hormonal replacement. However, an important dimension in the overall care of patients with pituitary tumours is the patient's situation in daily life, which consists of multiple symptoms, issues of fear and difficulties in receiving proper support $(15,16)$. Surgery can be perceived as a curative treatment without an awareness of the continued need for treatment and monitoring, and patients may struggle with how to understand the origin of their symptoms and signs post surgery (17). There are few studies focusing on patients with pituitary tumours and their experiences during the different phases of their illness based on their own narratives and, especially, covering the time before and after surgery. Such a perspective can contribute to a more comprehensive understanding of the patient's situation and can support healthcare professionals in optimising interventions to improve health. Therefore, the aim of this study was to explore experiences during pre- and postoperative care and recovery after surgery in patients with a pituitary tumour using a qualitative study design.

\section{Methods}

\section{Design and setting}

As the aim of this exploratory study was to understand patients' experiences, an interpretative approach was used within a qualitative design (18). The qualitative design provides an opportunity to explore lived experiences based on patients' point of view. This design is used to broaden the understanding of specific situations, specifically in this study, the pre- and postoperative care and recovery after surgery. To be able to explore the changing experiences during the illness trajectory, the study was performed with repeated interviews with each patient included. The plan was to interview each patient three times: before surgery, within the first week after surgery and approximately half a year after surgery. The study was performed at a University Hospital in Sweden between November 2014 and May 2016. The study complied with the principles of the Declaration of Helsinki and was approved by the Regional Ethical Review Board in Gothenburg (dnr. 595-14). Written informed consent was obtained from all participants included in the study.

\section{Study participants}

A total of 16 patients, ten men and six women, $>18$ years of age who underwent surgery for a pituitary tumour were consecutively recruited (Table 1). None of the patients had a pituitary carcinoma. At the time for inclusion, 13 patients were cohabiting and 3 lived alone. All patients were born in Sweden. Eight patients were studying or working and eight were retired. With respect to educational status, four had completed elementary school, five high school and seven a university degree. All patients underwent first time surgery using endoscopic transsphenoidal technique. Three patients underwent a second pituitary surgery during the study period, in two cases using endoscopic transsphenoidal technique and one case using a transcranial approach (Table 1). Endocrine evaluation was performed during data collection before and after surgery, with glucocorticoid, sex steroid and thyroid hormone replacement initiated if needed (Table 2). Evaluation of growth hormone deficiency was performed after each patient's last interview. None of the patients underwent radiotherapy or chemotherapy treatment during data collection. Only one patient with a hormone-producing adenoma received targeted medical therapy.

\section{Data collection}

Ten patients were interviewed according to the original design with three interviews. The remaining six patients were interviewed twice: before surgery and approximately half a year after surgery. Rapid discharge after surgery prevented interviews at discharge. A total of 42 interviews were accomplished of which 40 were held face-to-face and

This work is licensed under a Creative Commons Attribution-NonCommercial-NoDerivatives 4.0 Internationab ticense.ifica.com at 04/26/2023 12:29:59PM 
Table 1 Characteristics of included patients $(n=16)$.

\begin{tabular}{|c|c|}
\hline & No. of patients \\
\hline Age at inclusion, mean (range), years & $55(20-75)$ \\
\hline Gender, M/F & $10 / 6$ \\
\hline \multicolumn{2}{|l|}{ Diagnosis and tumour growth pattern } \\
\hline Non-functioning pituitary adenoma & 10 \\
\hline Hormone producing adenoma ${ }^{a}$ & 2 \\
\hline Other lesions in the pituitary ${ }^{b}$ & 4 \\
\hline Invasiveness (para sellar) & 10 \\
\hline \multicolumn{2}{|l|}{ Surgical treatment } \\
\hline Primary surgery, TS/TC & $16 / 0$ \\
\hline Re-surgery, TS/TC & $2 / 1$ \\
\hline
\end{tabular}

ane patient with acromegaly and one with Cushing's disease, both in biochemical remission after surgery. ${ }^{\mathrm{b} C y s t i c}$ lesion, craniopharyngioma, pituitary oncocytoma, postpartum choriocarcinoma.

TC, transcranial approach; TS, transsphenoidal approach.

two by telephone. The same person (A C O) performed all the interviews. The first interview was held at a neurosurgical inpatient unit on the day before surgery. The second interview was performed at an endocrine inpatient unit 6-7 days following surgery before discharge. The third interview was held 4-12 months after surgery at an endocrine outpatient unit. The interviews focused on patient's experiences of having a pituitary tumour and undergo surgery, and how this disease interfered with everyday life. Each sequential interview was connected back to the former to follow-up on important concerns.

\section{Analysis of the narratives}

The process of analysis followed a systematic cycle of four steps (18) and was performed by the nurse who performed the interviews (A C O) and three researchers (E J U, I B, S J). The transcripts from the interviews were initially read to find an understanding that reflected the fundamental meaning of the texts whereas recording and transcribed interviews were listened to and read repeatedly. Notes were made and a summary of basic

Table 2 Patients with pituitary tumours and their pituitary hormone deficiencies and replacement therapy $(n=16)$.

\begin{tabular}{|c|c|c|c|}
\hline & \multicolumn{3}{|c|}{ No. of patients } \\
\hline & Gonadotropin & ACTH & $\mathrm{TSH}$ \\
\hline \multicolumn{4}{|l|}{ Deficiency $^{a}$} \\
\hline Before surgery & 6 & 4 & 8 \\
\hline After surgery & 6 & 6 & 9 \\
\hline \multicolumn{4}{|c|}{ Hormone replacement therapy ${ }^{a}$} \\
\hline Before surgery & 5 & 4 & 8 \\
\hline After surgery & 5 & 6 & 9 \\
\hline
\end{tabular}

${ }^{a}$ Growth hormone deficiency and replacement therapy not shown as it was first evaluated and initiated after the end of data collection. $\mathrm{ACTH}$, adrenocorticotrophic hormone; TSH, thyroid-stimulating hormone. meanings of the texts were made. This was followed by a sentence-by-sentence analysis of all interviews. All analyses followed the principle of moving from the whole transcript to parts and then back to the whole again. The analyses were performed over time by first reading all interviews performed at different time points and, after that, reading and analysing all interviews for each patient over the trajectory. During the second step, themes began to emerge which allow an in-depth picture of the patients' perspectives on becoming ill, managing their existential concerns and experiencing support and lack of support. The third step in the cycle concentrated on relating the meaning of the result in each section back to the text as a whole so that a new, expanded understanding could be achieved. The final step of the process concerned the identification of passages representing a shared understanding between the researcher and the patients (18).

\section{Results}

The analysis revealed three processes covering the trajectory from diagnosis to inpatient care and surgery and, finally, to recovery after surgery. The processes, which occurred simultaneously, comprised the experience of symptoms and signs, the mastery of existential fears and experiences of support and lack of support (Fig. 1). Quotes are incorporated in the result section to enhance the understanding of the processes covering the trajectory.

\section{Experiencing symptoms and signs}

\section{From ambiguousness to lack of control}

The patients did not experience the period before diagnosis as a straightforward path. Some patients related stories of a long duration of illness which was characterised by a gradual onset of symptoms. Some had experienced a number of symptoms for several years such as impaired vision, loss of menstruation, fatigue, loss of initiative and headaches. The feeling of having lack of energy resulting in problems with managing everyday activities was a shortcoming the patients experienced before the confirmation of diagnosis. Further, to manage work, studies, household and social activities was shown to be an everyday struggle and the patients were left with a feeling of not recognising themselves and they felt dull and lazy. The patients also highlighted that relationships with family members and friends were strained as the

This work is licensed under a Creative Commons Attribution-NonCommercial-NoDerivatives 4.0 Internationab ticense.ifica com at $04 / 26 / 2023 \quad 12: 29: 59 \mathrm{PM}$ 


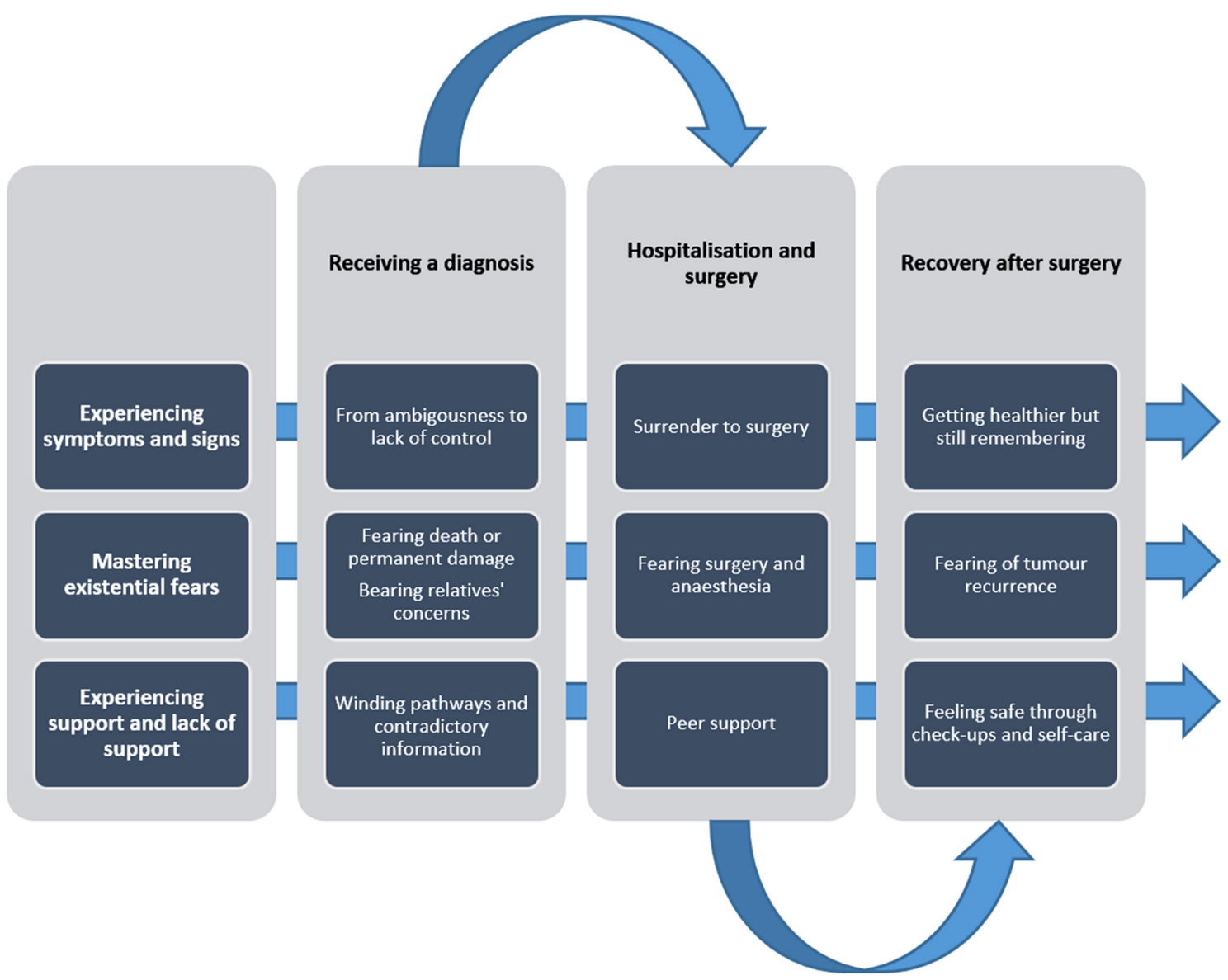

Figure 1

Three processes covering the trajectory from diagnosis to inpatient care and surgery and to recovery after surgery.

relatives expressed frustration with the patients' lack of energy, motivation and capacity. One man described 'Yes, I was very tired all the time ... could sleep several hours and far into the day. I did not know what was wrong ... but I ... my parents thought I was lazy. I thought that maybe I am...'.

Other patients went straight from health to illness with an acute onset of symptoms or a tumour discovered by accident. However, a pituitary tumour was not a diagnosis the patients had in mind, it took them off guard, and they expressed that it was hard to relate to the diagnosis. On the other hand, the diagnosis provided relief and gave confirmation that something was wrong. The patients also described that relatives were relieved because they were given a possible explanation of specific worries such as, for example, an insufficient sex life. Regardless of how the patients received their diagnosis or whether the diagnosis meant relief or not, it was difficult to relate to being ill. They felt strange to have something and expressed a loss of control and a lack of knowledge about their condition. One patient described the diagnosis as 'A slap in the face'.
Another patient said 'I don't want a diagnosis; I do not want to be ill'.

\section{Surrender to surgery}

The time period surrounding surgery entailed an ongoing negotiation of its advantages and disadvantages. Being confronted with the necessity for surgery the patients realised that they would get healthier with surgery and that they could get rid of distressful symptoms. Ambivalence was evident in the patients' narratives as they weighed undergoing surgery against continuing to allow the tumour to grow and refrain from surgery. A man described this ambivalence as follows: If everything goes as I want to, I'll be well, hopefully, but then you know there are risks too ... it was like choosing between the plague and cholera'.

Some patients stated that the decision for surgery was a medical decision with a limited involvement with them. Whatever the level of negotiation, with or without the 
surgeon, the process culminated in giving oneself over to the medical authorities, framed in a firm commitment to the decision for undergoing surgery. Once the decision to carry out the surgery was taken, high confidence for the responsible surgeon was expressed. One woman said 'My surgeon was very informative and I think it was good ... it was after that encounter [that] I wanted surgery. I did not want it earlier'.

\section{Getting healthier but still remembering}

During recovery patients typically expressed a strong positive change in their health as symptoms due to surgery and the disease had gradually disappeared, for example eyesight improved, sex drive returned. Furthermore, there was a more or less instant improvement in post-surgery symptoms with fewer headaches, easier breathing and less swelling in the nose. Patients described returning to everyday life as they returned to work, could start driving, travel and perform physical activity. Further, other aspects of everyday life concerning close relationships normalised, including normalised sex life and, thus, increased socialisation with their partners. Some patients referred to now being cured and completely healthy. However, some patients had not recovered to the same extent with respect to energy levels or fatigue and their narratives described a slower recovery: 'I feel better and better. But, if I've been working for some days and, if it has been stressful and messy, then I can be very tired when I get home, brain tired. Then I can sleep 3 or 4 hours when I get home. However, I feel that it's going in the right direction'.

Patients emphasised the importance of slow progress in returning to activities in everyday life. Being unable to perform leisure interests in the same way as before diagnosis or not to meet friends and family to the same extent was expressed as sad and disappointing: 'You do not know how far you can go and where the limits are, for example, in physical activity or work'.

A wish to leave the illness behind after surgery and move on with life was expressed. At the same time, the time period surrounding surgery was present in their mind and patients had strong memories of the illness trajectory in connection with surgery and, often, specifically from the magnetic resonance imaging examinations. Some of the patients who were on hormonal substitution also highlighted medications as something they had to deal and made them feel frustrated. However, some patients did not see any problems with the medications. Although medication made everyday life easier, patients expressed a lot of sadness about having to medicate throughout life. A man expressed 'I feel terribly irritated about having to take medicine for the rest of my life. Preferably, I would like to stop, but I know that I have to continue'.

\section{Mastering existential fears}

\section{Fearing death or permanent damage and bearing relatives' concerns}

Existential concerns were common in connection with diagnosis even though the patients were informed that the tumour was benign. The patients stressed the fear of being diagnosed with a tumour, a disease they experienced as frightening because they relate it to cancer, in particular if a family member had previously died from cancer: ' $A$ tumour in my brain, how fast will it grow? Can the physicians be sure it's benign before they have taken it out?'.

Patients also referred to how the diagnosis was a shocking experience for other people, specifically family members. Apart from handling their own anxiety and fear related to the tumour, the patients also had to be perceptive to the distress of family members. Some felt that the family members' worry far exceeded their own fears. As a response, some patients had to pretend to be healthier than they felt in front of their relatives. Patients were mostly well prepared for surgery and could cope with their own anxiety but sometimes their relatives could not. For some, the support from relatives was not sufficient for what they needed: 'He wasn't the support I had hoped for. It has been a mental strain for him. I have seen that. It became a bit too much for him'.

\section{Fearing surgery and anaesthesia}

The existential concerns related to surgery were worries of not being the same when waking up after surgery. The fact of having a pituitary tumour was manifest and eventual complications related to undergoing surgery could not be neglected. A patient interpreted the information from the physicians as follows: 'The physician said that it was a purely routine operation. But when I talked to another physician today, he said that it's quite not that simple. Afterwards, there may be complications like a leak in the brain. You can be forced to do the surgery again'.

Patients also expressed fear in relation to the localisation of the tumour and thereby being forced to undergo surgery in the head. A distress related to permanent damage was evident, for example related to eyesight and that the tumour would cause blindness. The distress of https://ec.bioscientifica.com https://doi.org/10.1530/EC-19-0202 (c) 2019 The authors Published by Bioscientifica Ltd
This work is licensed under a Creative Commons Attribution-NonCommercial-NoDerivatives 4.0 Internationab ticense.ifica com at $04 / 26 / 2023 \quad 12: 29: 59 \mathrm{PM}$ 
surgery also included a specific fear of anaesthesia related to not waking up. The fear of surgery could manifest in different ways. One man mentioned panic attacks during recovery and concluded: 'I must certainly have had anxiety before the surgery as well'. Typically, the patients were emotional and felt sad.

\section{Fearing of tumour recurrence}

Existential concerns during recovery entailed uncertainty and speculations about whether or not the tumour would return. A wish to leave the illness behind after the surgery and move on with life was expressed. One patient said 'I think that I am healthy now. Now they say after the last MRI that everything is good. No, I do not think it will come back. I cannot be sure, but I am trying not to think about it'.

\section{Experiencing support and lack of support}

\section{Winding pathways and contradictory information}

The time before diagnosis was, for many patients, a winding clinical pathway. Those who had experienced symptoms for some time knew something was wrong but they had not received any adequate answers or help within the healthcare system. Instead of getting help and support, patients felt that their symptoms were trivialised. Some were misdiagnosed with depression, attention deficit disorder or social phobia. This contributed to a feeling of relief as getting the correct diagnosis of a pituitary tumour finally gave an explanation and confirmation of the suspicion that something was wrong.

How information was delivered around the time for diagnosis was expressed as very important and some shared good experiences with physicians taking their time. Others got the news over the phone or in a room with other patients present. Information that was given with thoroughness, clearness, individualised and on an understandable level was highlighted as important. Confusion and anxiety was evident when different physicians had given conflicting information about whether the tumour should be treated surgically or not: 'Then he [the physician] told me that it will be surgery ... we want you to do that. Then she called [another physician] and said it's a tumour but there will be no surgery. It will be medications ... but oh my God ... she said the opposite. I thought: which one of you cares for me?'.

\section{Peer support}

During inpatient care, some patients expressed that they were still unprepared for everything that happened around them. However, many testified about professionals who explained, were educational and understood what they were going through. Some patients emphasised the importance of not only getting accurate up-to-date information, but also that it was given over and over again and with an emphatic sense. Support that was expressed as very helpful was peer support. Those patients who met other patients with the same diagnosis and who were undergoing the same type of surgery quickly became friends and compassionate to each other's situation. An understanding between patients was expressed based on the same experience. Since the healthcare professionals did not always have the time to talk, their peers were valuable: 'Well, the one who has gone through the same thing. That's what you need ... you don't have to explain because I see and feel that she [the peer] knows ... knows just what I mean ... how I'm experiencing ... she experiences the same thing'.

\section{Feeling safe through check-ups and self-care}

Patients expressed that medical follow-up worked well and they felt well taken care of. The follow-up contributed to a feeling of being safe. However, patients expressed a need for having someone to talk to about how they felt in general beyond the outcomes of the follow-up examinations. There were also expressions of lack of continuity with respect to which healthcare professional they would meet at the different time points during follow-up: 'I have met five to six endocrinologists during this time. Should it be like that? You must start over from the beginning each time'.

Reflections on what had been supportive through the pre- and postoperative care and recovery after surgery revealed a variety of self-care strategies initiated by the patients. Patients tried to maintain routines and a normal everyday life as far as possible and listened to their body to determine capabilities and limitations. Writing a diary during the experience helped some. Seeking support from others included seeking social support, talking to others with the same experiences and asking questions to healthcare professionals. Some put efforts into striving for a strong and positive mind: 'I tried to be strong; I have tried to be quite strong all the time. Even though it's so terrifying, I tried to think as positively as possible'.

\section{Discussion}

We have shown that the time surrounding diagnosis is critical for patients suffering from a pituitary tumour. A tumour in the head is often overwhelming. The diagnosis

This work is licensed under a Creative Commons Attribution-NonCommercial-NoDerivatives 4.0 Internationab ticense.ifica com at $04 / 26 / 2023 \quad 12: 29: 59 \mathrm{PM}$ 
brings forth existential questions about preserved personality and patients feel lonely and vulnerable. The period around the surgical treatment is characterised by surrendering to healthcare professionals in confidence. At the same time, patients are struggling with existential issues surrounding complications of surgery. The time during recovery reveals a normalisation of everyday life. However, there is a fear that the tumour will return.

Patients described the different symptoms as being ambiguous and difficult to understand before diagnosis to being clearly improved during recovery after surgery. During recovery, patients typically associated the improvement of their symptoms and general condition with the removal of the tumour rather than with the replacement of hormonal deficiencies. Many patients had gone into a chronic disease phase with life-long monitoring and treatment of hormonal replacement therapy (19), on which they do not obviously reflect. Some patients expressed that removal of the tumour was a cure for their condition. This phenomenon confirms the results from another study of pre- and postoperative experiences among patients with pituitary tumours which, in line with this, suggested that information and care should be improved after surgery (17). However, Thorne and Paterson (20) problematise the common perception in healthcare professionals that patients who do not show clear insight in their situation are in denial. The ability to keep the disease in the background does not necessarily mean denial; instead, it can be understood as a strategy where patients live in the present, allow well-being, joy of life and living as normal as possible rather than living their illness (20).

Patients struggled with existential concerns throughout their trajectory before and after surgery. Similar to the study in which patients underwent endoscopic transsphenoidal surgery for pituitary tumours (17), fear of surgery in the head, risk of complications and an expression of extensive trust in the surgeon was evident before surgery. Forthcoming surgery and its sequelae are often sources of distress among inpatients in general where major concerns are worries about not being able to fully recover and return to full health (21). Existential concerns about health and what the future would be like for oneself and loved ones are common (21, 22). Further, the fear of recurrence during recovery was evident in this study and has previously been highlighted as a central aspect of quality of life among patients treated for pituitary tumour $(15,16)$. Andela and colleagues (23) also have shown that relatives also often have existential concerns that include pituitary tumour recurrence.
Our results show how relatives play a central, but not always supportive, part in the patients' trajectory before and after surgery. Andela and colleagues (23) interviewed relatives of patients with pituitary tumours, not specifically during surgery, and showed that the disease had great impacts on family members, which is in congruence with how patients in this study described their relatives' situation. Relatives were so affected by the situation surrounding diagnosis and surgery that the patients had to prove themselves as healthier than they were so as to not be perceived as a burden for the relatives. Previous studies have shown wide negative influences on relatives when patients' well-being is negatively affected (15). Our findings revealed the significance of support coming from peers with the same diagnosis and going through the same surgical procedure. As patients had to deal with anxious relatives, their own existential concerns and symptoms as well as a lack of continuity and good communication with healthcare professionals, peer support seems to be of great value. The importance of peer support has been highlighted for patients with other chronic diseases (24) and it seems evident to also include this to a greater extent in the support for patients with pituitary tumours.

The design of this study with repeated interviews allowed us to explore the experiences and responses during different stages of the illness trajectory (25). Assuring trustworthiness, and thereby the rigour of the study, was maintained through several processes (26). Credibility was sought by ensuring that all patients' statements were represented as clearly as possible through verbatim quotations. The quotations represent all of the patients included in the study. Finally, an important quality criterion within a qualitative interpretative research process is that the authors are aware that understanding is gained from personal involvement in the reciprocal processes of interpretation (18). The analysis was undertaken with an extensive comparison of the interviews and numerous discussions between the four authors who performed the analysis with the aim of ensuring the most probable interpretation of the patients' narratives. The variety of preunderstanding of the researchers, one nurse involved in the care of the patients and three researchers with different clinical experience, created a base for a wide interpretation of data which enhances the trustworthiness of the study result. The study participants were consecutive patients with pituitary tumours needing surgical treatment not otherwise selected according to tumour type. This resulted in a heterogeneous population with respect to demographics, tumour type and perceived

This work is licensed under a Creative Commons Attribution-NonCommercial-NoDerivatives 4.0 Internationab kicense.ifica, com at $04 / 26 / 2023 \quad 12: 29: 59 \mathrm{PM}$ 
symptoms before and after surgery. The study did not catch the impact of initiating replacement therapy as this had already been done at the time of the first interview before surgery in almost all patients.

Based on the results from this qualitative study, we can conclude that patients with pituitary tumours need structured support which acknowledges physical, cognitive as well as emotional and existential concerns. The results indicate that both patients and their relatives are in need of peer support groups. Information related to diagnosis and surgical treatment should be adapted in relation to the loneliness and the existential seriousness of the situation that patients can perceive. Care and support for patients with pituitary tumours should preferably be organised based on continuity and in such a manner that a continuous and unbroken care pathway can be obtained from diagnosis, throughout tumour treatment to long-term follow-up.

\section{Declaration of interest}

T S has received lecture fees from Abbott. D S O has served as a consultant for Pfizer, Sandoz and Ipsen. G J has served as a consultant to Shire and AstraZeneca, and has received lecture fees from Ipsen, Novartis, Novo Nordisk, Pfizer, Sandoz, Merck Serono and Otsuka. The other authors have nothing to disclose.

\section{Funding}

This study was founded in part by grants from the Swedish state under agreement between the Swedish government and the county councils, the ALF-agreement (ALFGBG-719531) and from The Healthcare Board, Region Västra Götaland.

\section{Ethical approval}

All procedures performed in studies involving human participants were in accordance with the ethical standards of the institutional and/or national research committee and with the 1964 Helsinki declaration and its later amendments or comparable ethical standards.

\section{Author contribution statement}

All authors contributed to the design. E J U, S J, A C O and I B performed the data analysis, and interpretation of data. E J U and S J wrote the manuscript, and all other authors commented on and revised drafts of the manuscript critically. All authors read and approved the final version of the manuscript.

\section{Acknowledgements}

The authors wish to thank the patients that participated in the study and Peter Todd (Tajut Ltd., Kaiapoi, New Zealand) for third-party writing assistance in drafting of this manuscript, for which he received financial compensation.

\section{References}

1 Tjornstrand A, Gunnarsson K, Evert M, Holmberg E, Ragnarsson O, Rosen $\mathrm{T} \&$ Filipsson Nystrom $\mathrm{H}$. The incidence rate of pituitary adenomas in western Sweden for the period 2001-2011. European Journal of Endocrinology 2014171 519-526. (https://doi.org/10.1530/ EJE-14-0144)

2 Ntali G \&Wass JA. Epidemiology, clinical presentation and diagnosis of non-functioning pituitary adenomas. Pituitary 201821 111-118. (https://doi.org/10.1007/s11102-018-0869-3)

3 Olsson DS, Nilsson AG, Bryngelsson IL, Trimpou P, Johannsson G \& Andersson E. Excess mortality in women and young adults with nonfunctioning pituitary adenoma: a Swedish nationwide study. Journal of Clinical Endocrinology and Metabolism 2015100 2651-2658. (https://doi.org/10.1210/jc.2015-1475)

4 Higham CE, Johannsson G \& Shalet SM. Hypopituitarism. Lancet 2016388 2403-2415. (https://doi.org/10.1016/S01406736(16)30053-8)

5 Ding D, Starke RM \& Sheehan JP. Treatment paradigms for pituitary adenomas: defining the roles of radiosurgery and radiation therapy. Journal of Neuro-Oncology 2014117 445-457. (https://doi. org/10.1007/s11060-013-1262-8)

6 Olsson DS, Bryngelsson IL \& Ragnarsson O. Higher incidence of morbidity in women than men with non-functioning pituitary adenoma: a Swedish nationwide study. European Journal of Endocrinology 2016175 55-61. (https://doi.org/10.1530/EJE-16-0173)

7 Rosen T \& Bengtsson B-Å. Premature mortality due to cardiovascular disease in hypopituitarism. Lancet 1990336 285-288. (https://doi. org/10.1016/0140-6736(90)91812-O)

8 Hammarstrand C, Ragnarsson O, Hallen T, Andersson E, Skoglund T, Nilsson AG, Johannsson G \& Olsson DS. Higher glucocorticoid replacement doses are associated with increased mortality in patients with pituitary adenoma. European Journal of Endocrinology $2017 \mathbf{1 7 7}$ 251-256. (https://doi.org/10.1530/EJE-17-0340)

9 Olsson DS, Hammarstrand C, Bryngelsson IL, Nilsson AG, Andersson E, Johannsson G \& Ragnarsson O. Incidence of malignant tumours in patients with a non-functioning pituitary adenoma. Endocrine-Related Cancer 201724 227-235. (https://doi.org/10.1530/ ERC-16-0518)

10 Andela CD, Scharloo M, Pereira AM, Kaptein AA \& Biermasz NR. Quality of life (QoL) impairments in patients with a pituitary adenoma: a systematic review of QoL studies. Pituitary 201518 752-776. (https://doi.org/10.1007/s11102-015-0636-7)

11 Bulow B, Hagmar L, Orbaek P, Osterberg K \& Erfurth EM. High incidence of mental disorders, reduced mental well-being and cognitive function in hypopituitary women with GH deficiency treated for pituitary disease. Clinical Endocrinology 200256 183-193. (https://doi.org/10.1046/j.0300-0664.2001.01461.x)

12 Brummelman P, Elderson MF, Dullaart RPF, van den Bergh ACM Timmer CA, van den Berg G, Koerts J, Tucha O, Wolffenbuttel BHR $\&$ van Beek AP. Cognitive functioning in patients treated for nonfunctioning pituitary macroadenoma and the effects of pituitary radiotherapy. Clinical Endocrinology 201174 481-487. (https://doi org/10.1111/j.1365-2265.2010.03947.x)

13 Koltowska-Haggstrom M, Mattsson AF, Monson JP, Kind P, Badia X, Casanueva FF, Busschbach J, Koppeschaar HPF \& Johannsson G. Does long-term GH replacement therapy in hypopituitary adults with GH deficiency normalise quality of life? European Journal of Endocrinology 2006155 109-119. (https://doi.org/10.1530/eje.1.02176)

14 Olsson DS, Buchfelder M, Schlaffer S, Bengtsson BA, Jakobsson KE, Johannsson G \& Nilsson AG. Comparing progression of nonfunctioning pituitary adenomas in hypopituitarism patients with and without long-term GH replacement therapy. European Journal of Endocrinology 2009161 663-669. (https://doi.org/10.1530/EJE-090572) https://ec.bioscientifica.com https://doi.org/10.1530/EC-19-0202 (c) 2019 The authors Published by Bioscientifica Ltd
This work is licensed under a Creative Commons Attribution-NonCommercial-NoDerivatives 4.0 Internationab bicense.ifica com at $04 / 26 / 2023$ 12:29:59PM 
15 Andela CD, Niemeijer ND, Scharloo M, Tiemensma J, Kanagasabapathy S, Pereira AM, Kamminga NG, Kaptein AA \& Biermasz NR. Towards a better quality of life (QoL) for patients with pituitary diseases: results from a focus group study exploring QoL. Pituitary 201518 86-100. (https://doi.org/10.1007/s11102-0140561-1)

16 Simpson J, Heath J \& Wall G. Living with a pituitary tumour: a narrative analysis. Psychology and Health 201429 162-176. (https:// doi.org/10.1080/08870446.2013.840784)

17 Edem IJ, Banton B, Bernstein M, Lwu S, Vescan A, Gentilli F \& Zadeh G. A prospective qualitative study on patients' perceptions of endoscopic endonasal transsphenoidal surgery. British Journal of Neurosurgery 201327 50-55. (https://doi.org/10.3109/02688697.2012 .711497)

18 Fleming V, Gaidys U \& Robb Y. Hermeneutic research in nursing: developing a Gadamerian-based research method. Nursing Inquiry 200310 113-120. (https://doi.org/10.1046/j.14401800.2003.00163.x)

19 Romijn JA. The chronic syndromes after previous treatment of pituitary tumours. Nature Reviews Endocrinology 201612 547-556. (https://doi.org/10.1038/nrendo.2016.84)

20 Thorne SE \& Paterson BL. Two decades of insider research: what we know and don't know about chronic illness experience. Annual Review of Nursing Research 200018 3-25. (https://doi. org/10.1891/0739-6686.18.1.3)
21 Fridh I, Kenne Sarenmalm E, Falk K, Henoch I, Ohlen J, Ozanne A \& Jakobsson Ung E. Extensive human suffering: a point prevalence survey of patients' most distressing concerns during inpatient care. Scandinavian Journal of Caring Sciences 201529 444-453. (https://doi. org/10.1111/scs.12148)

22 Jakobsson S, Jakobsson Ung E, Lindstrom M, Eliasson B \& Ringstrom $\mathrm{G}$. Health status and most distressing concerns at admission and discharge reported by patients cared for at an internal medical care ward. Scandinavian Journal of Caring Sciences 201832 1168-1178. (https://doi.org/10.1111/scs.12562)

23 Andela CD, Tiemensma J, Kaptein AA, Scharloo M, Pereira AM, Kamminga NG \& Biermasz NR. The partner's perspective of the impact of pituitary disease: looking beyond the patient. Journal of Health Psychology 2017 [epub]. (https://doi.org/10.1177/1359105317695427)

24 Hoey LM, Ieropoli SC, White VM \& Jefford M. Systematic review of peer-support programs for people with cancer. Patient Education and Counseling 200870 315-337. (https://doi.org/10.1016/j. pec.2007.11.016)

25 Meleis AI, Sawyer LM, Im EO, Hilfinger Messias DK \& Schumacher K. Experiencing transitions: an emerging middle-range theory. Advances in Nursing Science 200023 12-28. (https://doi.org/10.1097/00012272200009000-00006)

26 Whittemore R, Chase SK \& Mandle CL. Validity in qualitative research. Qualitative Health Research 200111 522-537. (https://doi. org/10.1177/104973201129119299)

Received in final form 22 May 2019

Accepted 6 June 2019

Accepted Preprint published online 6 June 2019 https://ec.bioscientifica.com https://doi.org/10.1530/EC-19-0202 (c) 2019 The authors Published by Bioscientifica Ltd
This work is licensed under a Creative Commons Attribution-NonCommercial-NoDerivatives 4.0

Internationab ticense.ifica com at 04/26/2023 12:29:59PM 